\title{
UV Koruyucu Özellikli Mikrokapsül Hazırlanması ve \%100 Pamuklu Kumaşa
}

\author{
Gülden KOÇ ${ }^{*}$, Muharrem IMAL ${ }^{2}$, Gülizar MANTAR ${ }^{3}$ \\ ${ }^{1}$ Kahramanmaraş Sütçü İmam Üniversitesi, Tekstil Mühendisliği, Kahramanmaraş, Türkiye \\ ${ }^{2}$ Kahramanmaraş Sütçü İmam Üniversitesi, Makine Mühendisliği, Kahramanmaraş, Türkiye \\ ${ }^{3}$ Gaziantep Üniversitesi, Tekstil Mühendisliği, Gaziantep, Türkiye
}

\begin{abstract}
ÖZET: Bu çalışmada kompleks koaservasyon metodu kullanılarak UV koruyucu özellikli mikrokapsül üretimi ve kumaşa aktarılması amaçlanmıştır. Bu amaç için Arap zamkı ve Etil selüloz çeper madde olarak, $\beta$-karoten ve çay ektresi çekirdek malzeme olarak kullanılmıştır. Beş farklı çalışma denenmiş olup sonuçlar SEM ve Spektrofotometre ile ölçülmüştür.
\end{abstract}

Anahtar Kelimeler: Mikrokapsül, $\beta$-Karoten, Çay Ekstresi, Etil Selüloz, UV Koruyucu

\section{Producing of UV Protected Microcapsules and Transferring to \% 100 Cotton Fabric}

\begin{abstract}
In this study, it was studied to produce microcapsules UV protected property by complex coaservation method and transferring to fabric. For this aim, arabic gum and Ethyl cellulose used as shell metarials and $\beta$-Carotene and tea extract used as core metarials. Five different experiments were performed and the results were analyzed by SEM ( Scanning Electron Microscopy) and Spectrophotometer.
\end{abstract}

Keywords: Microcapsule, $\beta$-Carotene, Tea Exract, Ethyl Cellulose, UV Protected

\section{GİRIŞ}

Tekstil sektöründe katma değer kazandıran, rekabet ortamı yaratan ve pazar payını artıran fonksiyonel işlemlerin önemi gün geçtikçe artmaktadır. Tüketicinin isteklerini sadece estetik özellikler değil aynı zamanda fonksiyonel özelliklerde belirlemektedir. Mikrokapsülasyon teknolojisi son yıllarda tekstil materyallerine fonksiyonel özellik kazandırmada alternatif bir yol olarak kullanılmaktadır[1].

Yapılış şekillerine göre çeşitli mikrokapsül yöntemleri vardır. Ara yüzey polimerizasyonu metodu, in-situ polimerizasyonu, faz ayrımı (koaservasyon) yöntemi, sprey kurutma metodu bunlardan bazılarıdır. En uygun ve en yaygın olarak kullanılmakta olan kimyasal prosesler, basit ve kompleks koaservasyon ve in-situ polimerizasyonu teknikleridir. Tekstildeki mikrokapsülasyon uygulamaları, koku, kozmetik (nemlendirici vb), böcek kovucu madde, güç tutuşurluk maddeleri, vitamin ve ilaç aplikasyonları, anti mikrobiyal maddeler, boyarmadde ve FDM aplikasyonu şeklinde özetlenebilir[2-5].

Kabuk materyali, elde edilmek istenen etkiye, işlem şartlarına ve çekirdek materyaline göre değişmektedir. Birçok araştırmacı $1 \mu \mathrm{m}$ den küçük kapsülleri nanokapsüller, $1000 \mu \mathrm{m}$ den büyük kapsülleri makrokapsüller olarak ifade etmektedirler. Genellikle ticari kapsüller 3 ile $800 \mu \mathrm{m}$ arasında boyuta ve $\% 10-90$ çekirdek materyaline sahiptir [6-7].

Bu çalışmada kompleks koaservasyon yöntemi kullanılmıștır. Kompleks koaservasyon, farklı yüklere sahip iki kolloid kullanılarak gerçekleştirilmektedir. Hidrofilik kolloidin sulu çözeltisi hazırlandıktan sonra ortama farklı yükteki ikinci kolloid ilave edilmektedir. İkinci kolloidin ilavesinden sonra kolloidler çekirdek madde etrafinda toplanmaktadır. Böylece kompleks koaservasyona göre mikrokapsülasyon gerçekleşmektedir [8-9].

\section{MATERYAL ve YÖNTEM}

\subsection{Materyal}

Çalışmada çeper madde olarak arap zamkı, etil selüloz ve arap zamk1- etil selüloz, çekirdek madde olarak $\beta$-karoten, çay ekstresi ve $\beta$-karoten-çay ekstresi kullanılmıştır. $\beta$-karoten ve çay ekstresi ile UV koruyuculuk eldesi amaçlanmış̧ır[10-11]. Duvarın katılaşmasını sağlamak için formaldehit, çeper ile çekirdek maddeyi ayırmak için sodyum sülfat kullanılmıştır. Elde edilen kapsülleri \%100 pamuklu kumaşa aktarılmasını sağlamak için çapraz bağlayıcı kullanılmıştır [12-13]. 


\subsection{Metot}

Mikrokapsül üretimi için kompleks koaservasyon yöntemi ile 5 farklı çalışma yapılmıştır, elde edilen mikrokapsüller siyah ve beyaz olmak üzere iki farklı renkte örme kumaşa fluardda çapraz bağlayıcı ile aplike edilmiştir. Çalışma basamakları aşağıdaki gibidir.

\subsubsection{Mikrokapsül Üretimi}

İşlemlerde kullanmak için; Arap zamkı destile su ile $1 / 10$ luk, $40-50^{\circ} \mathrm{C}$ de, Etil selüloz etilen diklorür ile 1/10luk manyetik karıştırıcıda, $\beta$-karoten etil alkol ile 1/1000 lik ultrasonik karıştırıcıda çözelti şeklinde hazırlanmıştır. Mikrokapsül çalışmasında kullanılan kimyasal oranları Çizelge 1. de verilmiştir.
Çizelge 1. Mikrokapsül deney çalışmalarında kullanılan kimyasal malzeme oranları

\begin{tabular}{|c|c|c|c|c|c|}
\hline 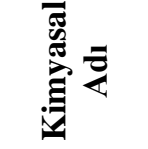 & 离 & 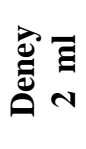 & 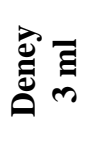 & 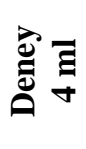 & ప \\
\hline $\begin{array}{c}\text { Arap } \\
\text { Zamk1 }\end{array}$ & 175 & - & 70 & 35 & 35 \\
\hline $\begin{array}{c}\text { Etil } \\
\text { selüloz }\end{array}$ & 175 & 70 & - & - & - \\
\hline $\begin{array}{c}\text { Çay } \\
\text { ekstresi }\end{array}$ & 25 & 5 & 5 & - & 5 \\
\hline$\beta$-karoten & 25 & 5 & 5 & 5 & - \\
\hline $\begin{array}{c}\text { Sodyum } \\
\text { Sülfat }\end{array}$ & 6 & 1 & 1 & 0.5 & 0.5 \\
\hline $\begin{array}{c}\text { Formalde } \\
\text { hit }\end{array}$ & 30 & 6 & 6 & 3 & 3 \\
\hline $\begin{array}{c}\text { Kapsül } \\
\text { oluşumu }\end{array}$ & Var & Yok & Var & Var & Var \\
\hline
\end{tabular}

Çizelge 2. Mikrokapsül üretim prosesi iş akış çizelgesi

\begin{tabular}{|c|c|c|c|c|c|}
\hline Deney No & 1 & 2 & 3 & 4 & 5 \\
\hline & $\begin{array}{l}\text { Çeper } \\
\text { madde }\end{array}$ & $\begin{array}{l}\text { Çeper madde } \\
+ \text { Çekirdek } \\
\text { madde }\end{array}$ & $\begin{array}{l}\text { Çeper } \\
\text { madde }\end{array}$ & $\begin{array}{l}\text { Çeper } \\
\text { madde }\end{array}$ & $\begin{array}{l}\text { Çeper } \\
\text { madde }\end{array}$ \\
\hline $\begin{array}{c}\text { Manyetik karıştırıcıda } \\
\text { karıştırma }\end{array}$ & $45 \mathrm{dk}$ & $20 \mathrm{dk}$ & $10 \mathrm{dk}$ & $10 \mathrm{dk}$ & $10 \mathrm{dk}$ \\
\hline \multirow[t]{2}{*}{$\begin{array}{l}\text { Ultrasonik karıştırıcıda } \\
\text { karıştırma }\end{array}$} & $10 \mathrm{dk}$ & $5 \mathrm{dk}$ & - & - & - \\
\hline & $\begin{array}{l}\text { Çekirdek } \\
\text { madde }\end{array}$ & & $\begin{array}{l}\text { Çekirdek } \\
\text { madde }\end{array}$ & $\begin{array}{c}\text { Çekirdek } \\
\text { madde }\end{array}$ & $\begin{array}{c}\text { Çekirdek } \\
\text { madde }\end{array}$ \\
\hline $\begin{array}{c}\text { Manyetik karıştırıcıda } \\
\text { karıştırma }\end{array}$ & $30 \mathrm{dk}$ & & $25 \mathrm{dk}$ & $25 \mathrm{dk}$ & $25 \mathrm{dk}$ \\
\hline \multirow[t]{2}{*}{$\begin{array}{c}\text { Ultrasonik karıştırıcıda } \\
\text { karıştırma }\end{array}$} & - & - & $5 \mathrm{dk}$ & $5 \mathrm{dk}$ & $5 \mathrm{dk}$ \\
\hline & \multicolumn{5}{|c|}{ Sodyum sülfat } \\
\hline \multirow[t]{2}{*}{$\begin{array}{c}\text { Manyetik karıştırıcıda } \\
\text { karıştırma }\end{array}$} & $15 \mathrm{dk}$ & $10 \mathrm{dk}$ & $5 \mathrm{dk}$ & $5 \mathrm{dk}$ & $5 \mathrm{dk}$ \\
\hline & \multicolumn{5}{|c|}{ Formaldehit } \\
\hline $\begin{array}{c}\text { Manyetik karıştırıcıda } \\
\text { karıştırma }\end{array}$ & $20 \mathrm{dk}$ & $20 \mathrm{dk}$ & $20 \mathrm{dk}$ & $20 \mathrm{dk}$ & $20 \mathrm{dk}$ \\
\hline
\end{tabular}

İşlem boyunca 1sıtma yapılmamış olup, pH değişmemiştir.(pH 4-5) Hazırlanan çözeltiler en az 12 saat olacak şekilde dondurucuda bekletilmiştir. Deney çalışmalarında kapsüllerin oluşup oluşmadığı mikroskop altında gözlenmiştir. Buna göre; $1,3,4$ ve 5 nolu deneylerde mikrokapsül eldesi sağlanmış, 2 numaralı deneyde kapsül oluşumu gözlenmemiştir. Şekil 1. de Deney 1-3-4-5 çalışmalarından elde edilen mikrokapsüllerin mikroskoptan alınan görüntüleri görülmektedir. Şekillerde de görüldüğü gibi kapsül oluşumu gözlenmiş ancak homojen bir dağılım elde edilememiştir. 


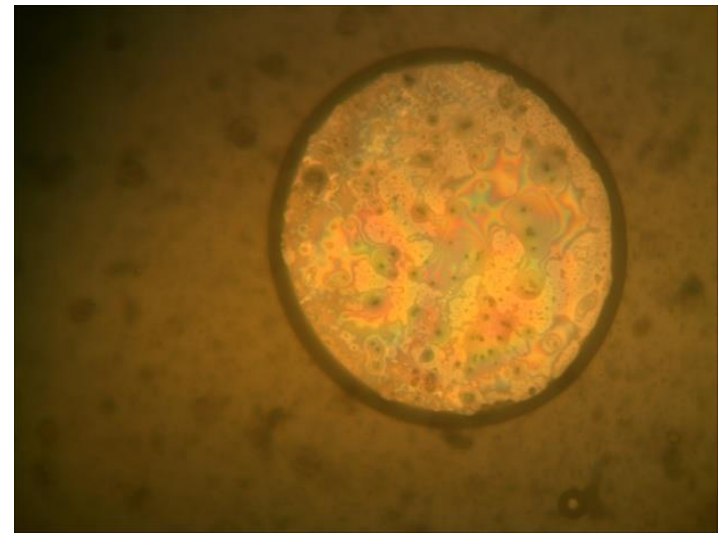

Deney 1

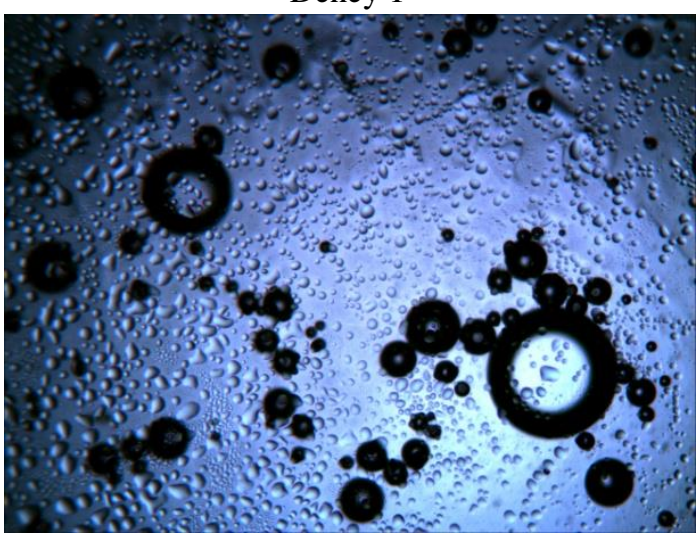

Deney 4

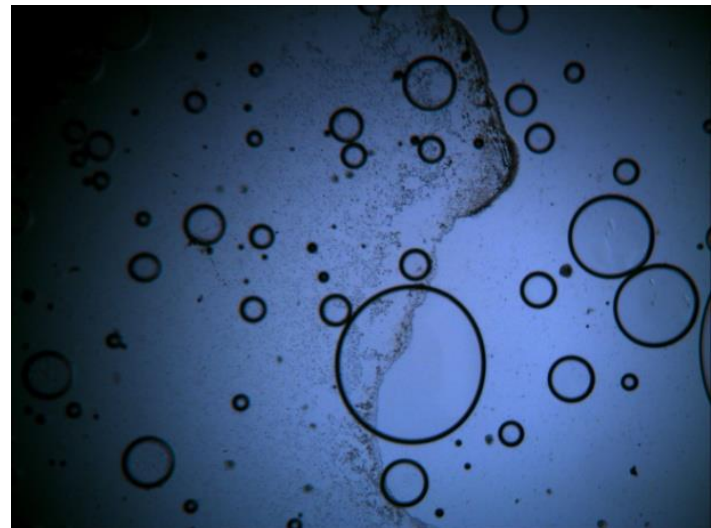

Deney 3

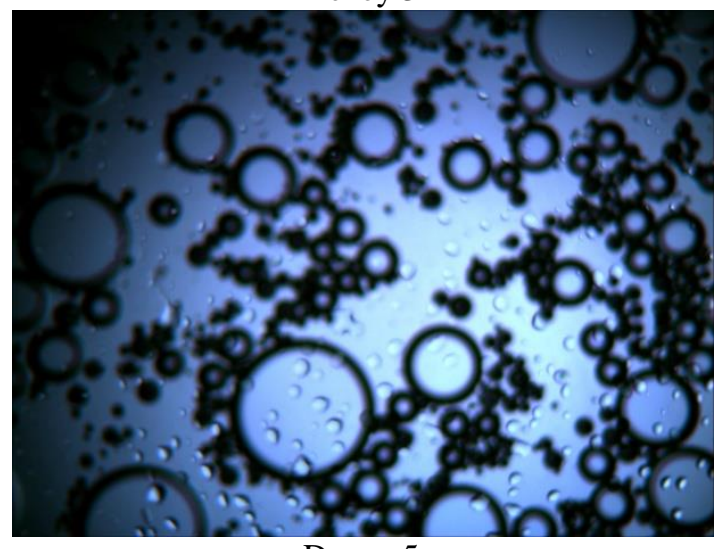

Deney 5

Şekil 1. Deney 1-3-4-5 çalışmalarında elde edilen mikrokapsüllere ait mikroskop görüntüleri

\subsubsection{Kumaşa Aplikasyon}

Kapsül oluşumu sağlanan çözeltiler değişik oranlarda çapraz bağlayıcı (Clariant orta derece BVA 26) ile karıştırılıp, siyah ve beyaz renkte örme kumaşlara aktarılmıştır.

Çözeltiler aşağıdaki oranlarda hazırlanmıștır;

a) $100 \mathrm{ml}$ mikrokapsülasyon çözeltisi $+30 \mathrm{ml}$ çapraz bağlayıcı

b) $100 \mathrm{ml}$ mikrokapsülasyon çözeltisi $+100 \mathrm{ml}$ destile su + $60 \mathrm{ml}$ çapraz bağlayıc c) $100 \mathrm{ml}$ mikrokapsülasyon çözeltisi $+200 \mathrm{ml}$ destile su + 90 ml çapraz bağlayıc1.

Kumaşlar Prowhite marka fluardda 3 bar basınçta, $2 \mathrm{~m} / \mathrm{dk}$ hız (\%78 AF)ile geçirilmiştir. Daha sonra etüvde $80^{\circ} \mathrm{C}$ de $10 \mathrm{dk}$ bekletilmiștir.

Kumaşa aplike edilen mikrokapsüller Zeis Evo LS10 marka SEM cihazında gözlenmiştir. Buna göre Deney 1 de elde edilen mikrokapsüller 3 farklı oranda da siyah ve beyaz renkteki \%100 pamuklu örme kumaşa bağlanmıştır.

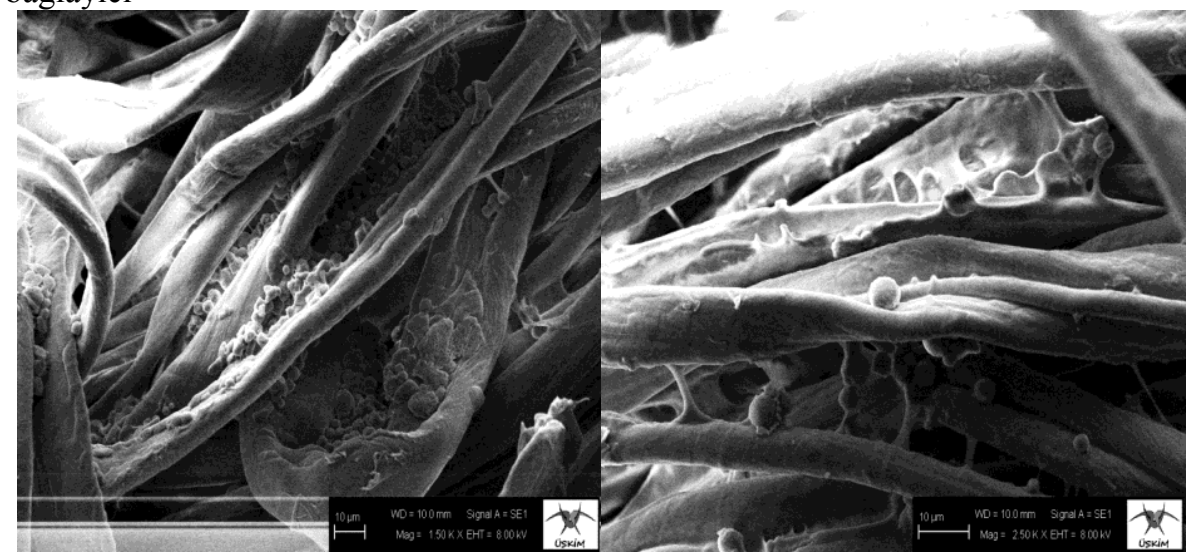

Şekil 2.Etilselüloz - arap zamkı - çay ekstresi - $\beta$-karoten ile mikrokapsül yapımı ve 100 ml mikrokapsülasyon çözeltisi $+30 \mathrm{ml}$ çapraz bağlayıcı ile kumaşa aktarılan SEM görüntüleri 


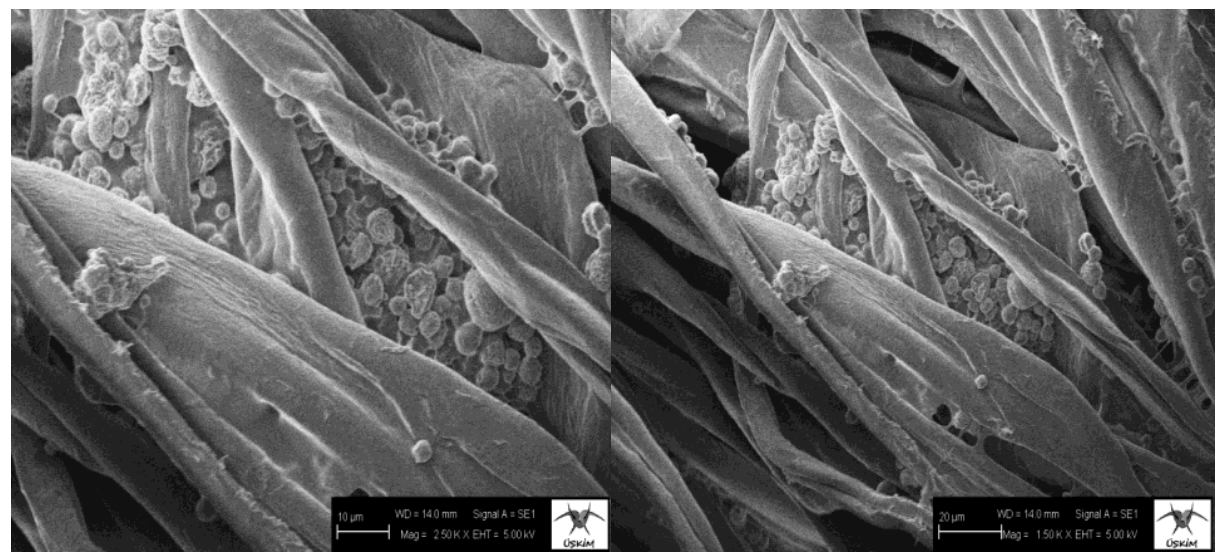

Şekil 3.Etilselüloz - arap zamkı - çay ekstresi - $\beta$-karoten ile mikrokapsül yapımı ve $100 \mathrm{ml}$ mikrokapsülasyon çözeltisi $+100 \mathrm{ml}$ destile su $+60 \mathrm{ml}$ çapraz bağlayıcı ile kumaşa aktarılan SEM görüntüleri

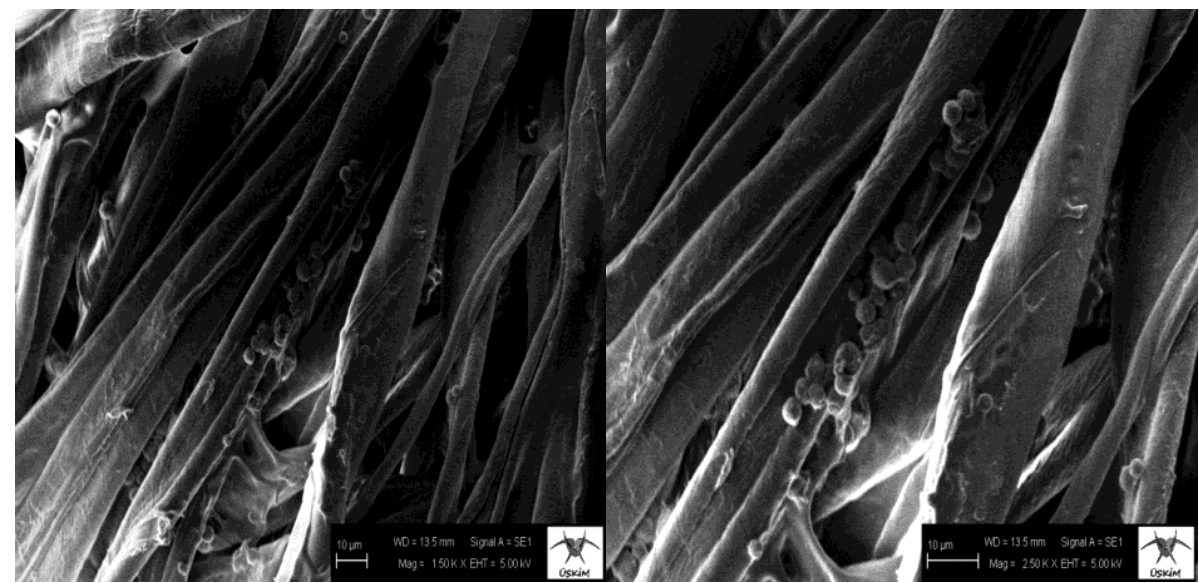

Şekil 4. Etilselüloz-arap zamkı-çay ekstresi- $\beta$-karoten ile mikrokapsül yapımı ve $100 \mathrm{ml}$ mikrokapsülasyon çözeltisi $+200 \mathrm{ml}$ destile su $+90 \mathrm{ml}$ çapraz bağlayıcı ile kumaşa aktarılan SEM görüntüleri

\subsubsection{Kumaşları UV Işını ve Gün Işı̆̆ı Altında Bekletme}

İşlem görmüş ve görmemiş kumaşlar 1-3-6-9-12-24 saat olmak üzere UV ışınına, Atlas Sun Test CPS+ markalı gün 1şı̆̆ı simülatöründe $16 \operatorname{saat}(7$ güne denk

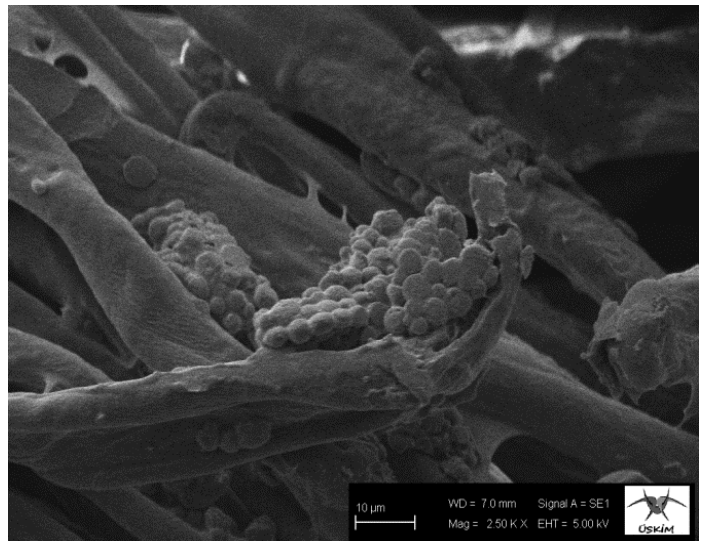

b1a gelmektedir) gün 1şı̆̆ına tabi tutulmuştur. SEM cihazında 12-24 saat UV ışını altında bekletilen kumaşlar ve gün 1şığı simülatöründe tutulan kumaşlarda renk ölçümleri yapılmış ve meydana gelen renk farklılıkları değerlendirilmiştir. Yapılan incelemelerde kumaşlar üzerinde mikrokapsül bulunmuştur.

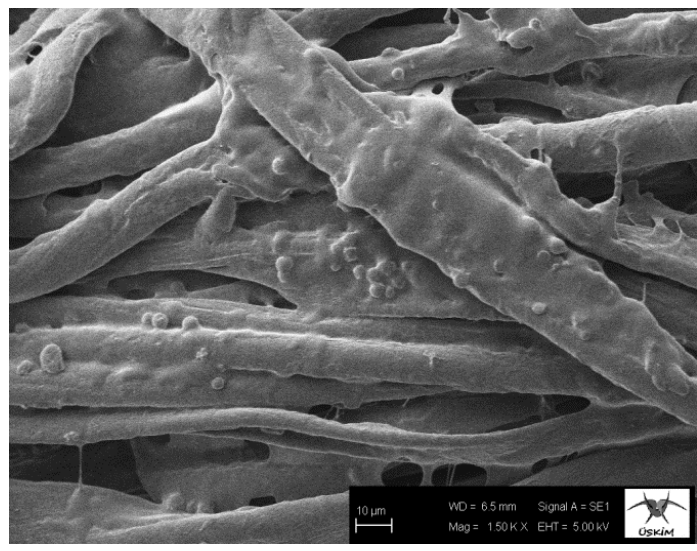

s1a

Şekil 5. 12 saat UV de bekletilen kumaşlardan alınan SEM görüntüleri 


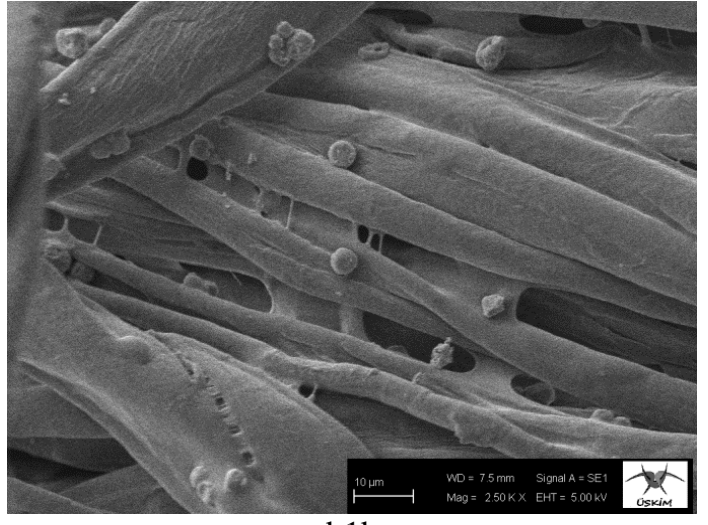

b1b

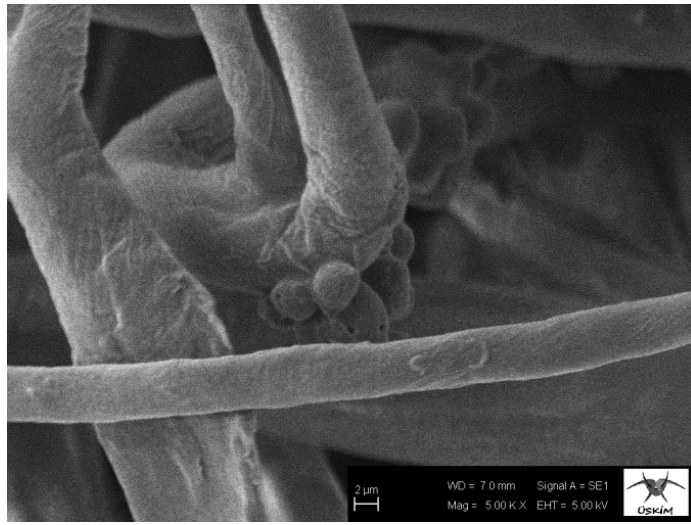

b1c

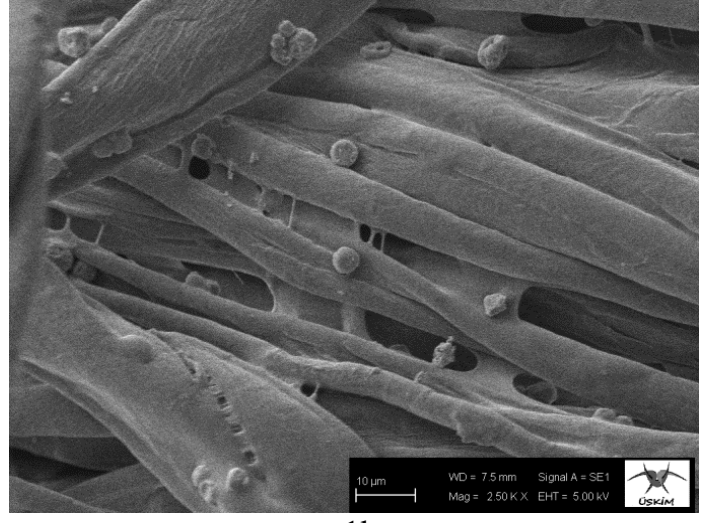

$\mathrm{s} 1 \mathrm{~b}$

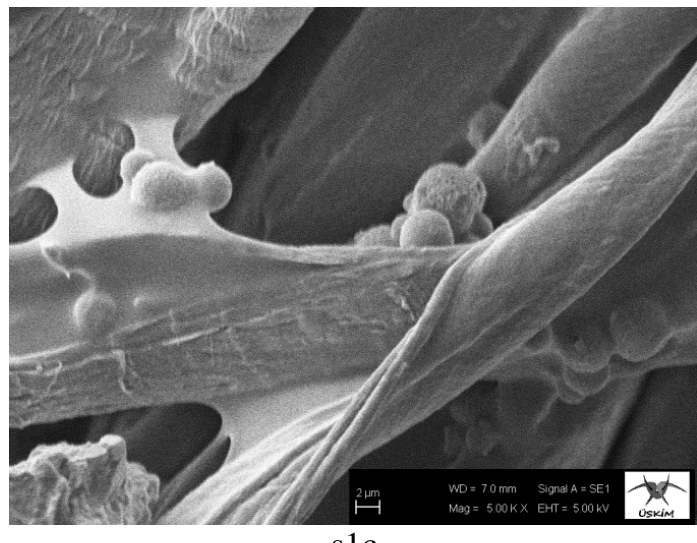

s1c

Şekil 5. 12 saat UV de bekletilen kumaşlardan alınan SEM görüntüleri

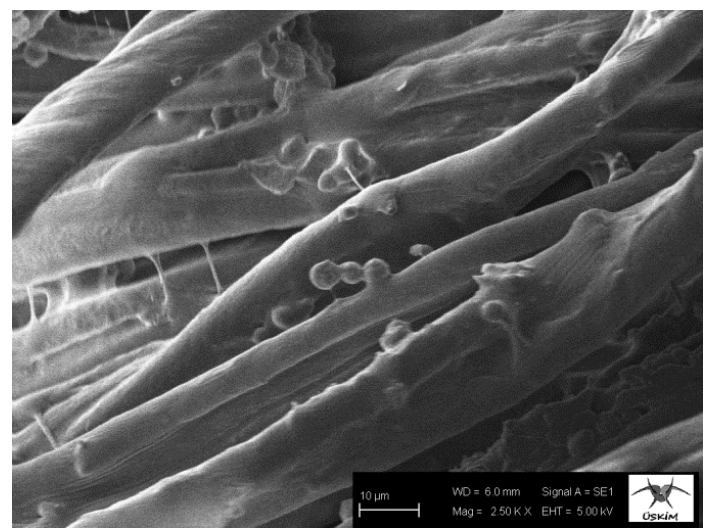

b1a

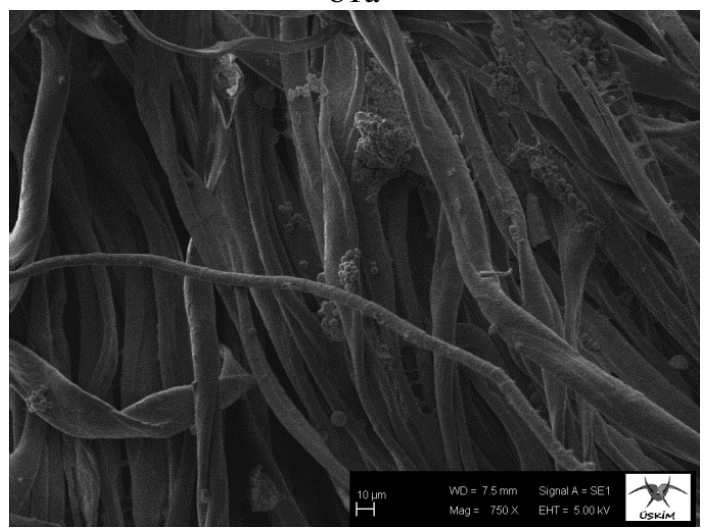

b1b

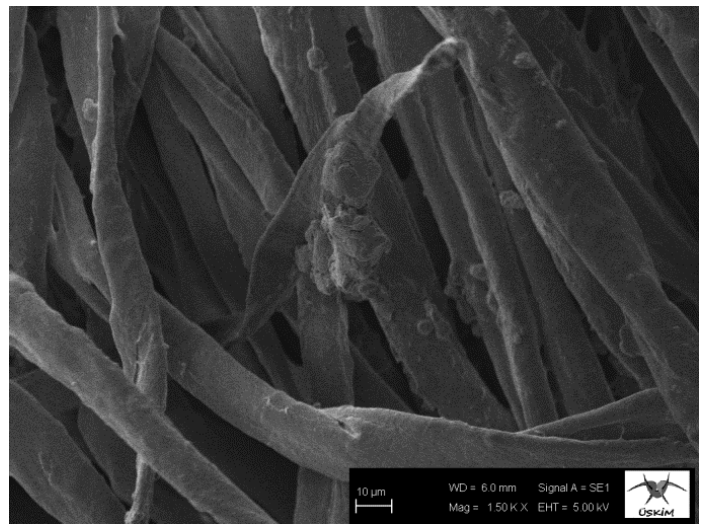

s1a

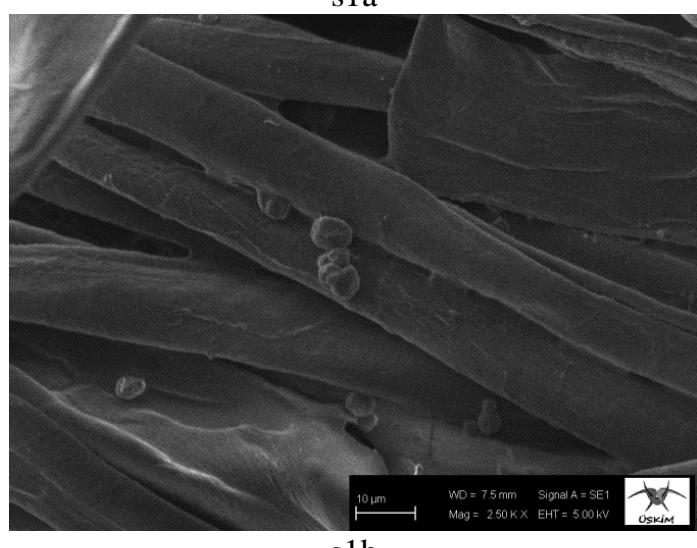

$\mathrm{s} 1 \mathrm{~b}$

Şekil 6. 24 saat UV de bekletilen kumaşlardan alınan SEM görüntüleri 


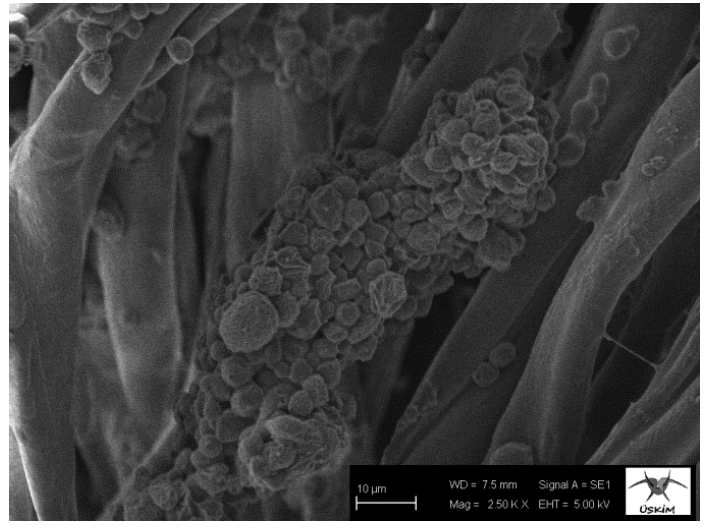

b1c

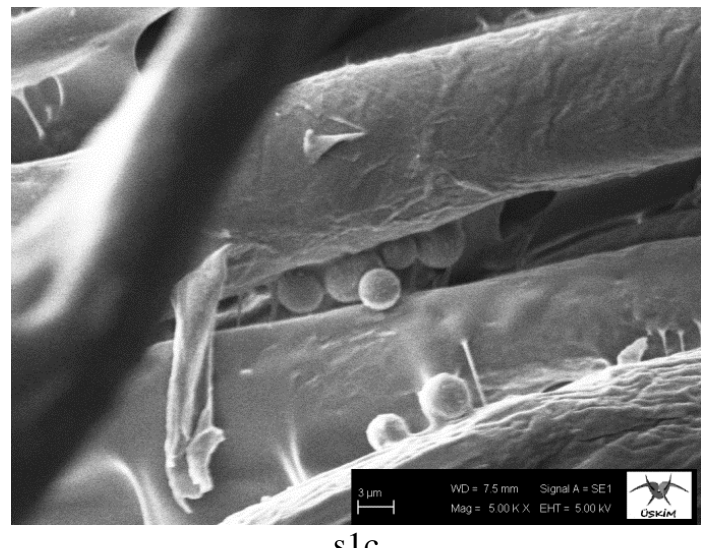

Şekil 6. 24 saat UV de bekletilen kumaşlardan alınan SEM görüntüleri
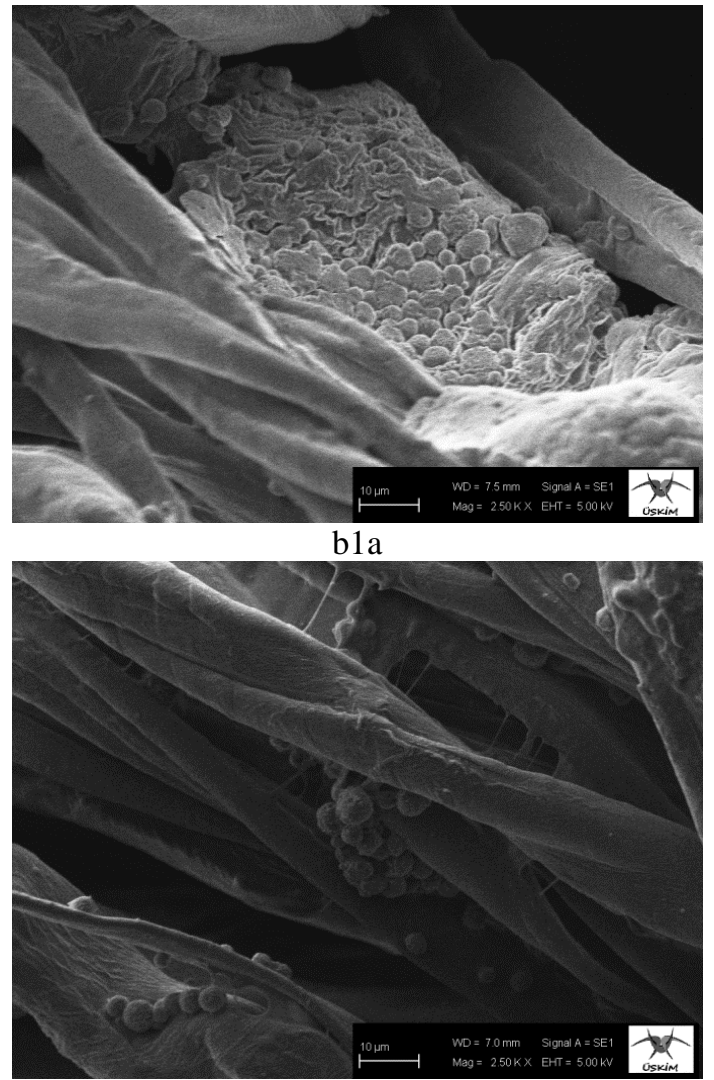

b1b

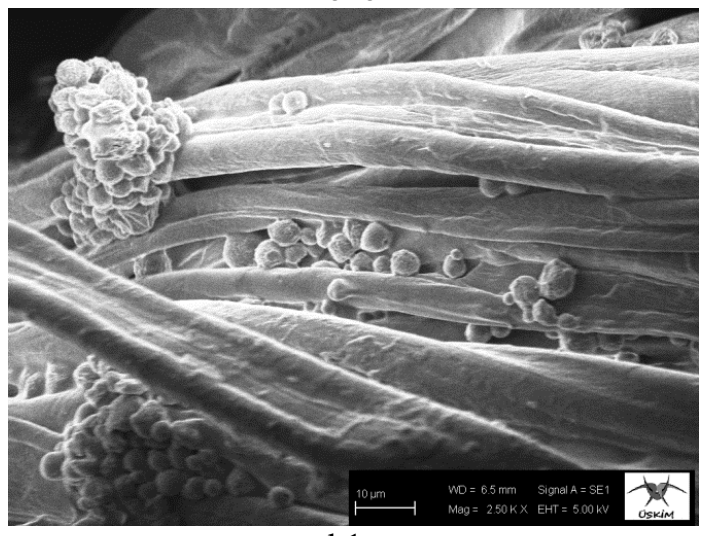

b1c

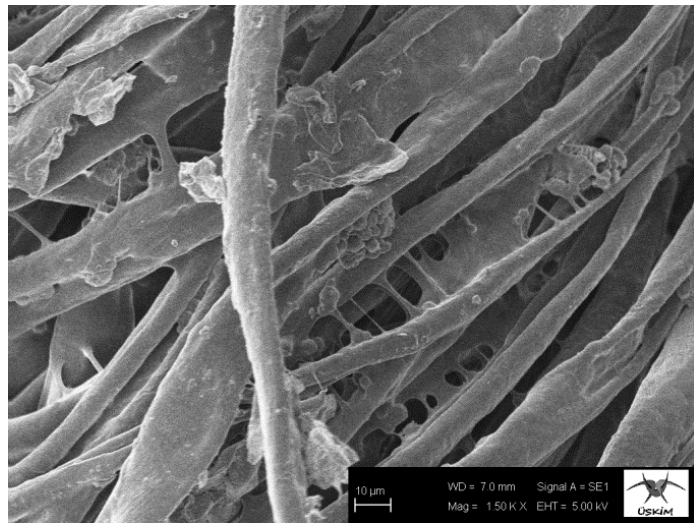

s1a

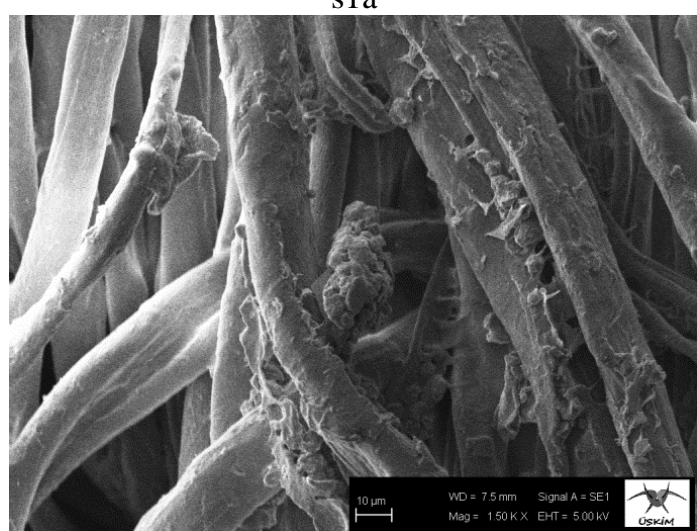

$\mathrm{s} 1 \mathrm{~b}$

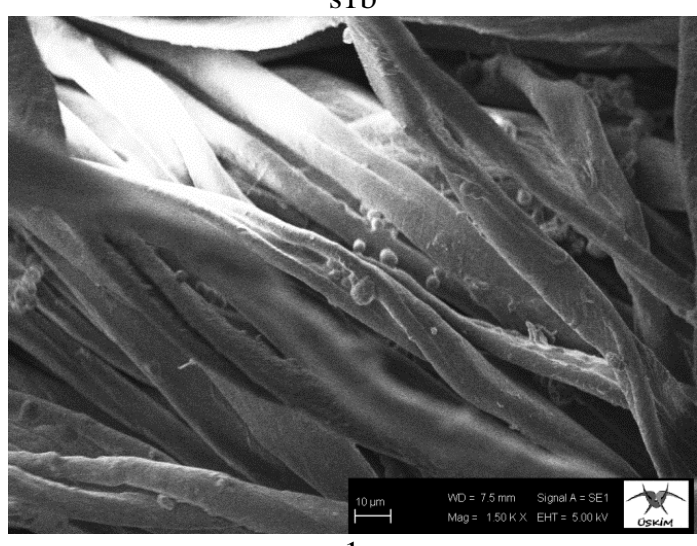

s1c

Şekil 7.Gün ışığı simülatöründe bekletilen kumaşlardan alınan SEM görüntüleri 


\subsubsection{Kumaşlarda Renk Ölçümü}

Renk ölçümleri Color i 7 Benchtop Spektrofotometre de yapılmıştır. Aşağıdaki Çizelge 3,4,5 ve 6 te verilen değerler bulunmuştur.

Çizelge 3. 12 saat UV de bekletilen kumaşların renk ölçüm sonuçları

\begin{tabular}{|c|c|}
\hline $\begin{array}{c}\text { Kumaşlar } \\
\text { (12 saat UV) }\end{array}$ & DEcmc \\
\hline b1a & 14,35 \\
\hline s1a & 2,60 \\
\hline b1b & 2,82 \\
\hline s1b & 2,77 \\
\hline b1c & 4,61 \\
\hline s1c & 0,88 \\
\hline
\end{tabular}

Çizelge 4. 24 saat UV de bekletilen kumaşların renk ölçüm sonuçları

\begin{tabular}{|c|c|}
\hline $\begin{array}{c}\text { Kumaşlar } \\
\text { (24 saat UV) }\end{array}$ & DEcmc \\
\hline b1a & 7,58 \\
\hline s1a & 4,89 \\
\hline b1b & 2,57 \\
\hline s1b & 4,44 \\
\hline b1c & 1,95 \\
\hline s1c & 3,38 \\
\hline
\end{tabular}

Çizelge 5. Gün Işı̆̆g simülatöründe bekletilen kumaşların renk ölçüm sonuçları

\begin{tabular}{|c|c|}
\hline $\begin{array}{c}\text { Kumaşlar } \\
\text { (Gün Işı̆̆ } \mathbf{l})\end{array}$ & DEcmc \\
\hline b1a & 9,26 \\
\hline s1a & 2,59 \\
\hline b1b & 0,26 \\
\hline s1b & 2,67 \\
\hline b1c & 3,59 \\
\hline s1c & 2,32 \\
\hline
\end{tabular}

Çizelge 6. 12-24 sa Uv de ve gün 1şığı simülatöründe bekletilen işlem görmemiş kumaşların renk ölçüm

\begin{tabular}{|c|c|}
\hline \multicolumn{2}{|c|}{ sonuçları } \\
\hline $\begin{array}{c}\text { İşlem Görmemiş } \\
\text { Kumaş }\end{array}$ & DEcmc \\
\hline 12 sa UV (beyaz) & 1,48 \\
\hline 12 sa UV (siyah) & 2,24 \\
\hline 24 sa UV (beyaz) & 2,04 \\
\hline 24 sa UV (siyah) & 3,28 \\
\hline Gün Işı̆̆ (beyaz) & 3,89 \\
\hline Gün Işı̆̆ı (siyah) & 0,95 \\
\hline
\end{tabular}

\section{SONUÇLAR}

Yapılan deneysel çalışmada; çeper madde olarak etil selülozun tek başına kullanıldığı denemelerde mikrokapsül elde edilememiş, arap zamk1 ile çalışıldığında mikrokapsül elde edilmiş, çeper madde olarak arap zamkı tek çalışıldığında mikrokapsül elde edilmiş fakat kumaşa aplikesinden sonra mikrokapsül gözlemlenememiştir.

Çekirdek madd $\beta$-karoten tek çalışıldığında kalın çeperli kapsüller, çay ekstresi tek çalışıldığında ince çeperli ve çok yoğun kapsül eldesi oluşmuştur.

Deneysel çalışmada kapsül eldesinin homojen ve eşit çaplı olmadığı, kumaşa aktarılan kapsüllerin de homojen dağılmadığı, yığılma halinde kaldığı gözlemlenmiştir. $\mathrm{Bu}$ durum yapılan işlemlerde (UV 1şı̆̆ında ve gün 1şı̆̆ında bekletme) sonuçların verimli olarak alınmasına engel olmuş, işlem öncesi ve sonrası kapsül yoğunluğunda değişme olup olmadiğ1 gözlemlenememiştir.

Hazırlanan deney çözeltilerinde $\beta$-karotenden kaynaklanan bir renklilik söz konusudur. Özellikle beyaz örme kumaşa aktarımında çözelti rengi kumaşı etkilemiştir. Aktarım da homojen gerçekleştirilemediğinden renk farklılı̆̆ özellikle beyaz kumaşta çok yüksek çıkmıştır. İşlem görmüş siyah kumaşın işlem görmemiş siyah kumaşa göre daha az renk değişimi gösterdiği, işlem gören tüm kumaşlarda keskin bir koku olduğu deney çalışmaları sırasında gözlemlenmiştir.

\section{TEŞEKKÜR}

Çalışmanın gerçekleştirilmesinde sağladıkları olanaklar ve destekler nedeni ile Kahramanmaraş Sütçü İmam Üniversitesi BAP Koordinatörlüğü, Prof. Dr. Dilek KUT, Prof. Dr. Murat TÜRKOĞLU, Doç. Dr. Cem GÜNEŞOĞLU, FİSTAŞ FANTAZİ İPLIKK FABRİKASI, ELVİN TEKSTİL ve ENSAR TEKSTILL e teşekkür ederiz.

\section{KAYNAKLAR}

[1]. Sarışık M. Tekstil Terbiye İşlemlerinde Mikrokapsülasyon Olanakları 27-28 Mayıs 2010 Tekstil Kimyasalları, Boyaları ve Prosesleri Sempozyumu-UŞAK

[2]. Güler Z., Kut D., 2011, Polyester Perdelik Kumaşta Isıl Regülasyon Sağlamaya Yönelik Mikrokapsül Hazırlanması Ve Uygulanması, Uludağ Üniversitesi Mühendislik-Mimarlık Fakültesi Dergisi, Cilt 16, Sayı 1 
[3]. Ghosh, S.K. (2006). Functional Coatings and Microencapsulation: A General Perspective. S.K. Ghosh. Functional Coatings by Polymer Microencapsulation içinde (1-28) Weinheim: WILEY-VCH Verlag GmbH \& Co. KGaA.

[4]. Celep Ş.,(2007), Nanoteknoloji Ve Tekstilde Uygulama Alanları", Yüksek Lisans Tezi, Çukurova Üniversitesi Fen Bilimleri Enstitüsü, Adana, $182 \mathrm{~s}$.

[5]. Önder E., Sarıer N., Çimen E., (2008), Encapsulation Of Phase Change Materials ByComplex Coacervation To İmprove Thermal Performances Of Woven Fabrics, Thermochimica Acta, 467, s.: 63-72.

[6]. Thies, C. (1996). A Survey of Microencapsulation Processes. S. Benita, (Ed.), Microencapsulation Methods and Industrial Applications içinde (1-21). New York, NY, USA; Marcel Dekker Incorporated.

[7]. Övez,B.,Yüksel,M., (2002), Parfümlerin Çapraz Bağlı Mikrokapsüllerden Yavaş Salgılanmaları, Çevre Koruma Dergisi, Cilt: 10 Sayı: 43, (2002), 26-29.

[8]. Erkan G. Bazı Antifungal Ajanların Mikrokapsülasyonu ve Tekstil Materyallerine Aplikasyonu Dokuz Eylül Üniversitesi Fen Bilimleri Enstitüsü Doktora Tezi Tekstil Mühendisliği Bölümü, Tekstil Mühendisliği Anabilim Dalı Eylül 2008

[9]. Kaş, S.H. (2002). İlaç taşıyıcı partiküler sistemler, A. Z. Gürsoy, (Ed.), Kontrollü salım sistemleri içinde (65-99). İstanbul; Kontrollü Salım Sistemleri Derneği Yayınları No:1.

[10]. M. Turkoglu and N. Cigirgil Black tea gel and its protection potential against UV International Journal of Cosmetic Science, 2007, 29, 437-442

[11]. Derviş E., Oral Antioksidanlar, Dermatoz 2011 ; 2(1) : 263-267.

[12]. Badulescu, R., Vivod, V., Jausovec, D., Voncina, B. (2008). Grafting of ethylcellulose microcapsules onto cotton fibers. Carbohydrate Polymers, 71, 85-91.

[13]. Nelson, G., Wales, D.S. ve Sagar, B.S. (1991). EP0511258 B1. 